Supporting material:

\title{
Morphology of the C3Ms
}

The morphology of the $\mathrm{Zn}-$ and $\mathrm{Nd}-\mathrm{C} 3 \mathrm{Ms}$ was studied with transmission electron microscopy (TEM). The contrast is enhanced compared to normal C3Ms owing to the presence of heavy metal ions. We find spherical micelles for both the $\mathrm{Zn}$ - and $\mathrm{Nd}-\mathrm{C} 3 \mathrm{M}$ systems with their radii less than 10nm, which is obviously far smaller than the results from DLS. This is because what we see from TEM is the metal-containing micelllar core, whereas the hydrodynamic radius from DLS is a summation of the corona (shell) and the core.
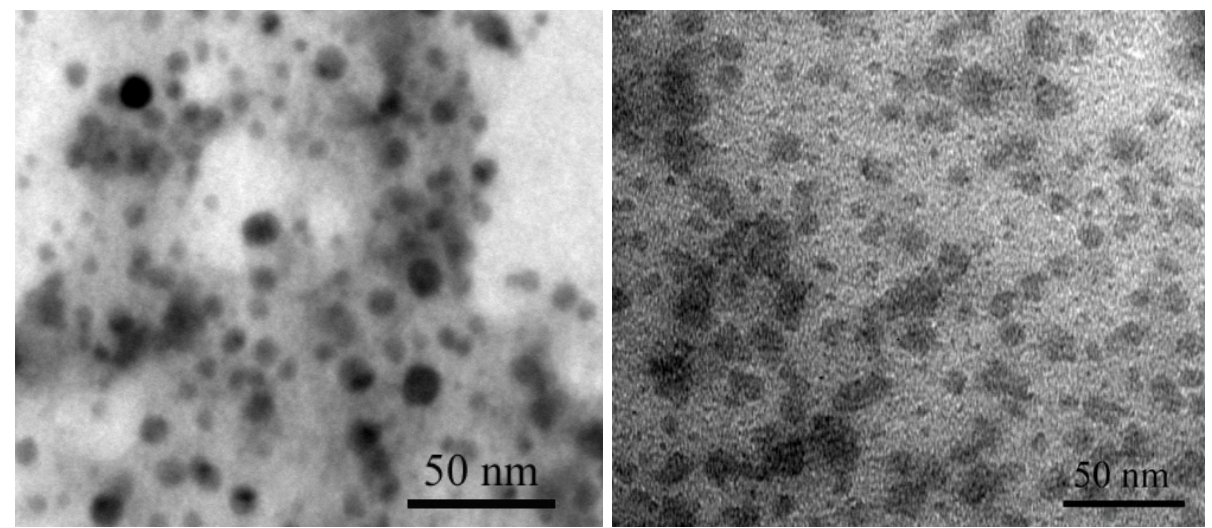

Figure 1. TEM results of $\mathrm{C} 3 \mathrm{Ms}$ formed in the titration of $\mathrm{P} 2 \mathrm{MVP}_{41}-\mathrm{b}-\mathrm{PEO}_{205}$ with $\mathrm{Nd}_{2}-\left(\mathrm{L}_{2} \mathrm{EO}_{4}\right)_{3}$ (left) and with $\mathrm{Zn}-\left(\mathrm{L}_{2} \mathrm{EO}_{4}\right)$ (Right) at $f$ - $=0.5$. 